\title{
ANÁLISE COMPARADA DO DIREITO BRASILEIRO E CALIFORNIANO SOBRE A TUTELA DO DIREITO À IMAGEM: PERSPECTIVAS DE UM DIREITO CIVIL CONTEMPORÂNEO
}

\section{COMPARATIVE ANALYSIS OF BRAZILIAN AND CALIFORNIAN LAW ABOUT PROTECTION OF THE RIGHT OF IMAGE: PERSPECTIVES OF A CONTEMPORARY CIVIL RIGHT}

\author{
${ }^{1}$ Isis Boll de Araujo Bastos \\ ${ }^{2}$ Flaviana Rampazzo Soares
}

\begin{abstract}
RESUMO
O direito à imagem, tutelado no ordenamento jurídico brasileiro, merece ser observado por meio do direito comparado. Analisar o direito californiano é fundamental para melhor compreender o direito brasileiro no que se refere ao direito de imagem e sua disposição para além da morte, pois referido sistema jurídico apresenta feições de forma e conteúdo diferenciadas em muitos aspectos, mas é tão protetivo quanto o direito brasileiro. Sob a perspectiva do princípio da autonomia privada e da liberdade, é possível verificar que pela via testamentária o titular do direito tem a possibilidade de preservar sua imagem para além de sua morte. $\mathrm{O}$ avanço tecnológico e, sobretudo, a rápida evolução dos mecanismos de manipulação digital de imagens permitem que pessoas falecidas sejam revividas em filmes e musicais, dentre outros. Porém, cabe ao titular do direito à imagem preservá-la mediante disposições testamentárias válidas e eficazes. Compreender os direitos da personalidade como expressão da dignidade da pessoa humana facilita a percepção do conteúdo e abrangência existencial (para além da dimensão meramente patrimonial) dessa disposição de última vontade, e o direito comparado auxilia na busca de melhores soluções às questões postuladas.
\end{abstract}

Palavras-chave: Direito comparado, Direito de imagem, Novas tecnologias, Sucessão testamentária

\begin{abstract}
The right of image, protected in the Brazilian juridical system, is worth being examined by means of comparative law. Analyzing Californian law is fundamental to better understand Brazilian law regarding the right of image and its implications after death, as several characteristics of Californian law are different from Brazilian law in terms of form and content, but they are equally protective. From the perspective of the principle of private autonomy and freedom, it is possible to notice that one can keep ones image after death by will. Technological advancements and particularly the fastdeveloping mechanisms of digital manipulation of images enable dead people to be revived in movies and songs, for example. However, it behooves the owner of the image right to preserve it through valid and effective testamentary disposition. Understanding personality rights as an expression of dignity of the human person enables the perception of existential content and comprehensiveness (beyond the mere patrimonial dimension) of the last will disposition, and comparative law favors the search for better solutions for issues deriving from that.
\end{abstract}

Keywords: Compared law, Image rights, New technologies, Testamentary succession

\footnotetext{
${ }^{1}$ Doutorado em Direito na Pontifícia Universidade Católica do Rio Grande do Sul - PUCRS, Rio Grande do Sul, (Brasil) Email: tutortreinamento@gmail.com

${ }^{2}$ Mestre em Direito pela Pontifícia Universidade Católica do Rio Grande do Sul - PUC, Rio Grande do Sul, (Brasil).
} 


\section{INTRODUÇÃO}

Recentemente, o falecimento do ator Robin Williams, ocorrido no estado da Califórnia, Estados Unidos da América (EUA), trouxe à tona o debate a respeito da restrição, por iniciativa de seu titular e em testamento, do uso da própria imagem, após sua morte ${ }^{1}$.

O testamento do ator foi elaborado, firmado e está sendo executado sob o sistema jurídico californiano, que possui peculiaridades que o diferenciam do brasileiro.

Esse tema tem uma conotação jurídica importante, porque trata da análise da possibilidade de harmonização entre direitos de personalidade e novas tecnologias, sob uma perspectiva de direito comparado, bem como a proteção jurídica do legado imaterial da pessoa, principalmente em tempos que os avanços tecnológicos permitem que uma imagem seja criada e manipulada de maneira livre, até mesmo interagindo com uma imagem real, pois os lindes entre o real e o virtual estão cada vez mais grises.

Tal fato, ressalta a rekvância da análise dos atos de disposição para o pós-morte nessa dimensão, relativa aos atributos pessoais, com índole extrapatrimonial direta e patrimonial indireta, porque permite duas abordagens relevantes: a primeira é a possibilidade de manter, na pessoa do titular, a disposição sobre o uso de sua imagem no período pós-morte, excluindo da seara do herdeiro essa prerrogativa e a segunda demonstra que o direito sucessório não tem conotação puramente material, servindo não apenas para tratar de questões relacionadas ao patrimônio, mas, também, abrindo espaço para que sejam tratados interesses de cunho existencial ou imaterial.

Expande-se, assim, o âmbito de autodeterminação humana em testamento, que, conforme mencionado, sempre foi permeado pelos ares do patrimonialismo, e agora está ampliando sua abrangência, para contemplar também (e com maior ênfase) as dimensões imateriais da pessoa.

Este artigo tem o objetivo de analisar esse cenário, e suas implicações jurídicas.

O problema da pesquisa analisará duas situações: de que forma é possível tutelar o direito à imagem após a morte do titular do direito? Qual é a abordagem desse tema no direito comparado?

Para a construção desta pesquisa optou-se em utilizar como método de abordagem o dedutivo, quando se partirá de aspectos gerais envolvendo o fenômeno da manipulação de

\footnotetext{
${ }^{1}$ No caso concreto, o ator Robin Williams restringiu o uso da sua imagem pelo prazo de vin te e cinco anos (Dis ponível em: <http://www.theguardian.com/film/2015/mar/31/robin-willia ms-restricted-use-image-des piteexisting-us-laws>. Acesso em: 05 de junho de 2015).
} 
imagem em direção ao específico estudo da disposição póstuma do uso da imagem, bem como da utilização do testamento como forma possível de preservar a vontade daquele que não deseja ter sua imagem utilizada no pós morte. (GIL, 2010 e 1999).

$\mathrm{Na}$ técnica de pesquisa privilegiar-se-á a coleta doutrinária e documental (GIL, 2010 e 1999) e, como método de procedimento, serão utilizados o documental quando serão desenvolvidos estudos com base na literatura sobre o assunto e análise de casos; e o comparativo, pois serão analisados casos do direito comparado e não apenas no âmbito jurídico brasileiro. Será realizada uma microcomparação, no sentido de que serão comparados institutos jurídicos específicos entre o Brasil e o estado da Califórnia, nos Estados Unidos da América (EUA). A escolha pelo estado Califórnia justifica-se por sua localização no distrito de Hollywood, cidade de Los Angeles, onde está estabelecida a parte mais expressiva da indústria cinematográfica estadunidense, e, assim, tem-se um estado com grande representatividade na área do direito de imagem, além de ter sido neste estado o falecimento e testamento do ator Robin Willia ms.

\section{O FENÔMENO DA MANIPULAÇÃO DIGITAL DE IMAGENS}

O fenômeno da tecnologia está transformando paradigmas, em uma velocidade crescente. Forçadamente, esse fenômeno pede passagem no horizonte do direito.

Avanços tecnológicos possibilitam a criação de doppelgängers (réplicas) digitais de qualquer pessoa, através da técnica da Computer Graphic Imagery (CGI), a qual permite a manipulação de imagens de forma realista e dinâmica.

O uso de tais recursos tem permitido certas criações inimagináveis, servindo sobremodo às indústrias fonográfica e cinematográfica.

Uma das possibilidades trazidas pela tecnologia CGI, é a de que a imagem de uma pessoa falecida seja "revivida" pela criação e manipulação digital de imagem, muitas vezes conjugada com a voz. A edição de imagens, aliada ao uso da técnica rotoscoping, permite a formação de impressionantes imagens em 3D, de pessoas vivas ou falecidas.

A disponibilidade da tecnologia, aliada a ânsia do público de reviver seus ídolos que morreram, ou de conjugar os trabalhos destes com o de artistas vivos, ainda que fruto de uma criação artificial, é campo fértil à indústria do entretenimento, como visto, por exemplo, na produção de imagens holográficas de Michael Jackson dançando e cantando no Billboard 
Music Awards ${ }^{2}$ ou na impressionante "apresentação póstuma" do falecido cantor Elvis Presley com a cantora Celine Dion ${ }^{3}$.

No campo cinematográfico, a tecnologia permitiu que o personagem interpretado pelo ator Tom Hanks (Forrest Gump) interagisse com o falecido ex-presidente estadunidense Richard Nixon 4 .

Em 2015, no filme Velozes e Furiosos 7, o ator Paul Walker foi "ressuscitado" para a finalização das cenas com o auxîlio das imagens geradas em computador e com dois irmãos do ator nas cenas que o rosto não poderia ser visto. ${ }^{5}$

Assim, tem sido cada vez mais comuns os casos de espetáculos, apresentações, programas ou transmissões, que utilizam, por diversos meios (televisão, internet, etc.) imagens holográficas de pessoas falecidas ${ }^{6}$. Dessa forma, o falecimento não mais impede as pessoas de manterem-se presentes e atuantes em novos filmes, anúncios publicitários, ou apresentarem-se artisticamente, criando a possibilidade de que as pessoas possam licenciar suas imagens digitais, e seguir suas carreiras após a morte.

Mas, em que medida o direito (notadamente o tratamento dos direitos de personalidade e o direito sucessório) pode permear esse fenômeno tecnológico, sobretudo quando a pessoa cuja imagem será utilizada, não mais está viva para manifestar a sua vontade? Esse aspecto será abordado a partir do próximo tópico.

\section{PODER DE DISPOSIÇÃO SOBRE USO PÓSTUMO DE IMAGEM NO DIREITO CALIFORNIANO}

É em razão das consequências possíveis provindas dos avanços tecnológicos mencionados, que o ator Robin Williams entendeu, ainda em vida, que deveria proteger-se de práticas indesejáveis, o que o fez através de testamento (Living Trust).

\footnotetext{
${ }^{2}$ Disponível em: <http://www.billboard.com/articles/events/bbma-2014/6092040/michael-jackson-hologrambillboard-music-awards>. Acesso em 26 jul. 2015.

${ }^{3}$ Disponível em: <https://www.youtube.com/watch?v=demh7Whc96s $>$. Acesso em 26 jul. 2015.

${ }^{4}$ Disponível em: 〈https://www.youtube.com/watch?v=GCkz7gzeQYM>. Acesso em: 26 jul. 2015.

5 Notícia disponível em: <http://www.bbc.com/portuguese/noticias/2015/04/150401_paul_walker_ressucitado_velozes_furiosos_rb>. Acesso em: 11 ago. 2015.

${ }^{6}$ Tem se tornado comum a criação de "parcerias" entre artistas vivos e mortos, à revelia destes. Assim, por exemplo, a notícia da "colaboração póstuma" de Michael Jackson em clipe e música de Justin Timberlake, em notícia com o seguinte teor: "Justin Timberlake lembra Michael Jackson em novo clipe de parceria.

Colaboração póstuma 'Love neverfelt so good' ganhou vídeo nesta quarta. 'Discípulo' dança como o 'rei do pop' em frente a imagens antigas em telão." Disponível em: 〈http://g 1.globo.com/musica/noticia/2014/05/justin timberlake-lembra-michael-jacks on-em-novo-clipe-de-parceria.html>. Acesso em: 15 de jul. 2015.
} 
Seu testamento tratou de questões patrimoniais e extrapatrimoniais, inclusive sobre alguns direitos de personalidade, especialmente, no que respeita ao tema deste artigo, ao direito de imagem

De acordo com Festas (2009, p. 32, 62-63 e 390-394) a doutrina refere a existência de duas teorias que tratam do direito de imagem, quais sejam, a teoria monista e a teoria dualista.

A primeira considera o direito à imagem como um direito de personalidade que atribui ao seu titular a defesa desse legítimo interesse em face de ingerências alheias indevidas, assim como the permite o poder de disposição, mediante a possibilidade de obtenção de benefícios por sua exploração.

Por isso, a teoria monista não desvincula aspectos patrimoniais e extrapatrimoniais relacionados a imagem, sendo a teoria adotada no direito brasileiro.

A teoria dualista, por outro lado, desdobra o direito à imagem em right to privacy e rigth to publicity, ambos autônomos entre si, o primeiro reputando a imagem como uma das expressões intangíveis da privacidade (dela derivada, e não independente) e tutelando valores pessoais da personalidade nessa esfera, e o segundo, tratando da dimensão patrimonial da imagem, passível de exploração econômica.

Ao contrário das leis de direitos autorais, patentes e marcas, o right of publicity não tem sua fonte a partir da Constituição Federal ou da legislação do Congresso estadunidense, mas, sim tem sua gênese na doutrina do common law, e evoluiu a partir do right of privacy, que é criação das Cortes Estaduais. Em algumas jurisdições, como a da Califórnia, o direito de publicidade foi reconhecido por meio de legislação estadual (MARTIN JR, 1996, p. 107).

Quanto ao right of publicity, o seu debut ocorreu em 1953, quando foi reconhecido pela primeira vez no case Haelan Laboratories, Inc. v. Topps Chewing Gum, Inc. O juiz Jerome Frank afirmou, nesse julgado, que "além e independentemente do referido direito de privacidade, um homem tem direito no valor de publicidade de sua fotografia, ou seja, o direito de usufruir do privilégio exclusivo de publicar a sua imagem" (MARTIN JR, 1996, p. 109).

O testamento do ator Robin Williams, conforme antes referido, foi lavrado segundo as leis vigentes no estado da Califórnia ${ }^{7}$, que é o Estado onde o ator residia ao tempo da morte

\footnotetext{
${ }^{7}$ Cópia em arquivo PDF do "Robin William Trust" está disponível em: <http://www.hollywoodreporter.com/thresq/robin-williams-restricted-exploitation-his-785292?utm_source=twitter $>$. Acesso em: 25 jul. 2015. O trecho que interess a este trabalho tem o seguinte teor: "4.3.1.1. Specific Gifts of tangible personal property and real property. The trustee shall distribute the following tangible personal property and real property: (a) All ownership interest in the right to Settlor's name, voice, signature, photograph, likeness and right of
} 
e, no sistema do common law, em que os Estados Unidos da América (EUA) são um representante típico, costuma-se aplicar a teoria dualista do direito de imagem.

Assim, no caso do ator mencionado, houve tutela testamentária dos denominados rigths of publicity. $\mathrm{O}$ ator utilizou a via testamentária para manter a sua imagem a salvo de exploração publicitária, incluindo a impossibilidade de uso de sua imagem (estática ou dinâmica), nome, voz e assinatura por um período de vinte e cinco anos, a contar da sua morte, também dispondo sobre a posse de seu vestuário, joias, fotos pessoais tomadas antes de seu último casamento, recordações e prêmios recebidos da indústria do entretenimento.

$\mathrm{O}$ estado da Califórnia tem dois sistemas de right of publicity: o regulamentado por lei (Statutory right of publicity) e o do common law, ambos protegendo a pessoa contra a exploração não autorizada de nome ou imagem $^{8}$, mas cada um com suas particularidades ${ }^{9}$. Esclarece Glancy (1979, p. 2). que, nos Estados Unidos da América (EUA), o direito à privacidade como um conceito jurídico, é uma construção relativamente recente, concebida inicialmente em um estudo publicado em dezembro de 1890 por dois jovens advogados de Boston, Samuel Warren e Louis Brandeis, denominado "Rigth to privacy", Publicado na Harvard Law Review n. 193, em 1890.

privacy/publicity ( sometimes referred to as "right of publicity") to the Windfall Foundation, a California Nonprofit Corporation (The Windfall Foundation), subject to the restriction that such right of publicity shall not be exploited for a 25 year period commencing on the date of Settlor's death. If the windfall foundation shall not then exist or if contributions to the Windfall Foundation shall not then qualify for the charitable deduction pursuant to Sections 170(c) and 2055(a) of the Internal Revenue Code, the Trustee shall distribute such right of publicity to such one or more charitable organizations with a similar purpose to that of the Windfall Foundation as the Trustee shall select, contributions to which shall qualify for the charitable deduction pursuant to sections 170(c) and 2055(a) of the Internal Revenue Code. (b) subject to subparagraph (c), below, all of Settlor's clothing, jewelry, personal photos taken prior to his marriage to Susan, Settlor's memorabilia and awards in the entertainment industry and the tangible personal property located at 1100 Wall Road, Napa, CA that the Trustee determines not to sell shall be distributed do Settlor's then living children in substantially equal shares as they shall agree. In the event the children are not able to agree on the division of the foregoing tangible personal property, the Trustee shall decide, in the Trustee's reasonable discretion, which items shall be distributed to each child, and which items shall be gifted to one or more charitable organizations (including the institution holding Settlor's archived material) deemed appropriate by the Trustee and which qualify for the charitable deduction pursuant to Sections 170(c) and 2055(a) of the Internal Revenue Code. The Trustee's determination and decision with regard all of to the foregoing in this subparagraph shall be final and absolute."

${ }^{8}$ Porém, a doutrina adverte que o $§ 3344$ do Código Civil da Califórnia tem um âmbito protetivo mais restrito que o da common law action, a qual protege a identidade pessoal, e is so se dá porque o $\$ 3344$ impõe a responsabilidade de quem fizer o uso indevido apenas se a apropriação desautorizada de imagem tiver ocorrido com o conhecimento do ofensor (uso consciente da ilicitude) e que esse uso es teja vinculado a uma finalidade comercial, para fatos ocorridos no Estado da Califórnia (alínea "n" do § 3344.1 do Código Civil californiano). (MATHEWS; LANCASTER, 2013, p. 34).

9 "O segundo sentido de "Common Law" se refere ao contraste existente entre, de u m lado, a "Common Law" o direito criado pelo juiz (judge-made law) e, de outro, o direito criado pelo legislador postado fora do Poder Judiciário (Statute Law). Portanto, neste segundo sentido, de "judge-made law", "Common Law" opõe-se a "Statute Law" entendido este direito como aquele resultante dos "enactements of legislature" (tratados internacionais, Constituição Federal, constituições estaduais, leis ordinárias federais e estaduais, regulamentos administrativos federais, estaduais e locais." (SOARES, 1997, p. 180)). 
O primeiro sistema (Statutory right of publicity) é formado pelo Código Civil Californiano (California Civil Code) ${ }^{10}$. O $§ 3344$ do mencionado Código protege a imagem, nome, voz e assinatura do titular, contra ingerências alheias indevidas e desautorizadas.

Conforme a alínea (a) do referido $§ 3344$, quem, consciente e desautoriadamente, utilizar o nome, a voz, a assinatura ou imagem (ou qualquer expressão semelhante ${ }^{11}$ ) alheia, por qualquer forma, em produtos, negócios ou bens, ou utilizando tais expressões de personalidade para obter se fazer passar por outra pessoa e disso tirando algum proveito, responderá pelos danos sofridos pelo titular do direito (na quantia em que comprovar ter sido prejudicado - incluindo perdas de lucros -, num mínimo de setecentos e cinquenta dólares).

A indenização não se limita estritamente ao prejuízo financeiro sofrido. A jurisprudência também costuma considerar o "prejuízo para a paz, felicidade e sentimentos", bem como "lesão ao status profissional e valor futuro de publicidade" experimentada, como um resultado prejudicial direto do uso não autorzado [conforme Waits v. Frito-Lay Inc., 978 F.2d 1093 (9th Cir. 1992)] (BIEDERMAN , 2007, p. 246).

A regra sob análise ainda permite a fixação de indenização punitiva em favor da vítima $^{12}$. Disposição em semelhantes termos consta no $\S 3344.1$ (a) (1), o qual trata especificamente da regulamentação dos direitos de personalidade, na fase post-mortem, diferenciando-se, em termos de redação, apenas em relação a quem se deve pedir autoriação para uso de nome, imagem, voz ou assinatura e a legitimidade de postulação de indenização.

Segundo a alínea (i) do $§ 3344.1$ do Código Civil californiano, a proteção ao direito de imagem contempla a reprodução de imagem, sob o aspecto estático ou dinâmico (em movimento), vídeos ou transmissões de televisão ao vivo, se a imagem do falecido for facilmente identificável (assim entendido se for razoavelmente reconhecida pela mera análise da imagem a olho nu).

Por interpretação, não apenas protege a representação física, mas, também, protege a imagem virtual (imagens processadas digitalmente), nome e voz.

Para saber se o uso do nome, imagem, voz ou assinatura alheia é regular ou irregular, no caso Newcombe v. Adolf Coors Co., 157 F.3d 686, 692 (9 Cir. 1998) ${ }^{13}$, ao analisar-se a

\footnotetext{
${ }^{10} \mathrm{O}$ texto do Código Civil da Califórnia está disponível na página oficial do Estado da Califórnia, disponível em: $<\mathrm{http}$ ///leginfo.legis lature.ca.gov/faces/codes_displayexpandedbranch.xhtml?tocCode=CIV\&division=4.\&title $=\&$ part $=\&$ chapter $=\&$ article $=>$. Acesso em: 02 ago. 2015. As decisões do Nono circuito (United States Courts for the Ninth Circuit) estão dis poníveis em: 〈http://www.ca9.uscourts.gov/rules/>. Aces so em: jul. 2015.

${ }^{11}$ Um desenho, por exemplo, tal como ocorreu em Newcombe v. Adolf Coors Co., 157 F.3d 686, 692-93 (9th Cir. 1998), um robô, se for suficientemente detalhado, [White v. Samsung, 971 F.2d 1395, 1397 [(9th Cir. 1992)].

12 O Código Civil da Califórnia limita as punitive damages aos casos de "oppression, fraud, or malice.” (\$3294).

${ }^{13}$ Charkalian adverte que a definição de likeness na composição da "identidade pes soal", no case Newcombe $v$. Adolf Coors Co. seria um "confuso quebra-cabeças". (CHAKALIAN, 1999, p. 131).
} 
incidência do referido parágrafo, afirmou-se que devem ser respondidos os seguintes questionamentos: 1. A pessoa apontada como ofensora fez uso consciente (sabia ou deveria saber) dos atributos de personalidade alheios? 2. Esse uso foi feito com fins comerciais? 3. Havia uma conexão direta entre o uso e o objetivo comercial desse uso? Se a resposta aos três questionamentos referidos for sim, nos termos desse precedente, é possível a responsabilização.

Isso se confirma pela leitura $\S 3344,1$ (h), do Código Civil californiano, o qual dispõe que, para se ter a proteção legal, o direito da pessoa falecida deve ter tido "valor comercial no momento da sua morte, ou por causa de sua morte".

No sistema da common law, no âmbito do right of publicity, costuma-se referir jurisprudencialmente que, aquele que reclamar por uso indevido de imagem, deve demonstrar: (1) o uso da imagem ou nome, juridicamente tutelados; (2) a apropriação do nome ou imagem por parte de quem é demandado; (3) a ausência de consentimento e (4) o dano decorrente do uso desautorizado [conforme especificado no precedente White v. Samsung, 971 F.2d 1395, 1397 (9th Cir. 1992) ${ }^{14}$ ].

O case citado demonstra que o sistema do Common Law é mais amplo que o sistema codicístico californiano, pois não exige que o uso do nome, imagem ou voz tenha propósito lucrativo, e tuteh a "identidade" pessoal, para além de apenas nome ou imagem [Waits v. FritoLay Inc., 978 F.2d 1093 (9th Cir. 1992)] (MARTIN JR, 1996, p. 110). Segundo a doutrina, a proteção à imagem contra seu uso desautorizado, ainda que sem fim lucrativo, se dá por força da primeira emenda da Constituição estadunidense (RAYSMAN , 2002, p.32).

A postulação de indenização em caso de uso indevido de imagem pode ser feita com base tanto no direito comum, quanto no Código Civil californiano (conforme o próprio Código prevê, na alínea (m) do $§ 3344$ ).

De acordo com a doutrina, o right of publicity, ao contrário do right to privacy, continua, ainda que ocorra a morte do titular da imagem ${ }^{15}$.

\footnotetext{
${ }^{14}$ Referido julgado trata do uso da imagem de um robô com características semelhantes a uma artista de programa de entretenimento, em posição e em cenário muito parecidos com a da artista, que postulou indenização por uso desautorizado de imagem. Foi determinado o dever de indenizar, com base no dever de proteção da identidade pessoalquando, pelas circunstâncias da publicidade, fica visível que o "robô" corresponderia a representação de uma famosa artista (BIEDERMAN, 2007, p. 247). Essa decisão judicial foi criticada por Braatz, o qual ressaltou que tal decisão significou que o common law, em matéria de right of publicity na califórnia, teria se expandido ilimitadamente, ao ponto em que juízes e advogados estariam inseguros em suas fronteiras, pois a simples lembrança dos telespectadores quanto a uma celebridade passaria a servir como base para uma demanda fundada na violação do right of publicity na Califórnia. Além dis so, referido autor alega que a decisão não teria deixado claro até que ponto, em sua totalidade, a Primeira Emenda e a mera paródia (não lesiva) constituem defes as válidas nas ações de right of publicity.(BRAATZ, 1994, p. 221).

${ }^{15}$ Mas nem todos os Estados nos EUA entendem dessa forma, conforme alerta Raysman (2002, p. 9-34).
} 
A Primeira Emenda constitucional é mais relevante nos casos de right of publicity no âmbito do common law. Mas, quando os casos envolvem demandas com base tanto no common law quanto no código civil californiano, a análise da Primeira Emenda costuma se sobrepõe a ambos.

Mas, segundo Martin Jr., em 1979, no precedente Lugosi v. Universal Pictures, a Suprema Corte da Califórnia declarou que, embora o right of publicity proteja contra o uso não autorizado do nome, imagem ou personalidade, este direito não seria transmissível e expiraria após a morte da pessoa então protegida (MARTIN JR, 1996, p. 117).

Como resultado desse precedente, um demandante que procura proteger os interesses de publicidade com valor comercial, pode ser instado a recorrer a um outro caminho, que seria a propositura de uma ação judicial mais tradicional e aceitável (em vez de utilizar a proteção prevista no Código Civil californiano), tal como uma reivindicação por infração de marca (service mark infringement claim), pois a indenização concedida pode ser monetariamente semelhante em um ou outro fundamento e também porque essa proteção pela service mark infringement claim não exige demonstração imediata de uma perda econômica (HENEGHAN, WAMSLEY, 1982, p. 115). E é para uma melhor proteção jurídica, e também para possibilitar o pleno uso dessa medida, que muitos artistas registram seu nome como marca.

E, quando se trata de aspectos no âmbito de regramento da federal copyright law, costuma-se rejeitar pretensão que seja fundada com base no Código Civil californiano [Laws v. Sony Music, 294 F. Supp.2d 1160 (C.D. Cal 2003)].

Segundo Martin Jr. (1996, p. 131), permitir que a imagem digital de pessoa falecida seja utilizada livremente significaria enriquecer injustamente criadores digitais de celebridades, privando os legítimos representantes do falecido (herdeiros, cessionários dos direitos do falecido, etc.) do direito de defesa contra usos desautorzados, abrindo as portas à exploração imoral da imagem da celebridade falecida.

Vê-se, assim, que o conteúdo normativo do Código Civil californiano expressa um sentido mais restritivo na possibilidade de obtenção de indenização. Nessa linha, o § 3344 alínea (d), do Código Civil californiano estabelece que, para utilizações relacionadas a qualquer notícia, assuntos públicos ou transmissão de esportes ou qualquer campanha políica, o uso da imagem, nome ou voz pode ser feito, ainda que sem autorização do titular (dispositivo esse repetido, ao se tratar da imagem de pessoa falecida, na alínea j).

O Statute Law, relacionado ao direito de privacidade estadunidense, reconhece que "nesta esfera de colisão entre as reivindicações de privacidade e as da liberdade de imprensa, os interesses de ambos os lados são enraizados nas tradições, e são preocupações 
significativas da sociedade" (LEWIS; CRICK, 2014, p. 133). No entanto, dado o papel central que desempenha discurso público nos EUA, até mesmo a própria corte que primeiro adotou o common law privacy right, reconheceu que o direito à privacidade é limitado pelo direito de expressão e publicação em relação aos temas em que o público possa ser legitimamente interessado. Este princípio tem-se mantido como um guia da jurisprudência estadunidense sobre direito de privacidade.

No que concerne a legitimação tanto para consentir com o uso de imagem de pessoa falecida quanto para postular indenização em caso de uso indevido de imagem, pós-morte, é atribuída, conforme o caso: (a) a quem for definido em testamento, (b) a quem for o titular de tal direito em razão de negócio jurídico regular, (c) ou a quem for herdeiro, na forma do $\S$

3344.1 (b) e (d $\left.{ }^{16}\right)$, do Código Civil californiano.

Mas, o registro da claim, perante o Secretary of State, para postular indenização por uso indevido de nome, voz, assinatura e imagem de pessoa falecida, somente pode ser feito até setenta anos a contar da morte do titular originário de tal direito (conforme $§ 3344$, alíneas (f) (2) e (g) do Código Civil californiano) ${ }^{17}$.

\section{CONTEÚdo dA PROTEÇÃO A IMAGEM, NOME, VOZ E ASSINATURA NO SISTEMA JURÍDICO CALIFORNIANO, EM COTEJO COM O BRASILEIRO}

Em linhas gerais, o direito californiano não destoa do teor do direito brasileiro no que concerne aos conceitos gerais de imagem, nome, voz e assinatura.

A diferença é que o Código Civil californiano utiliza distintamente as expressões photograph e likeness.

Photograph, na forma do $\$ 3.344$ (b) (3) do Código Civil Californiano, é mais que o mero retrato. Inclui imagens estáticas ou em movimento, contemplando também vídeos ou transmissões televisivas $^{18}$ cuja retratação do titular da imagem seja "facilmente identificável" (assim considerada a que se poderia "razoavelmente determinar"). No entanto, imagens de multidões, como em vias públicas ou em eventos esportivos, desde que não retratem as

\footnotetext{
${ }^{16}$ A alínea (d) referida faz uma divisão a respeito da composição da "maioria" para a autorização, o que não será minudenciado nesse artigo para que não se alongue em ponto que não é o seu foco.

${ }^{17}$ No Brasil, o artigo 41 da Lei n. 9.610/1998 estabelece que os direitos patrimoniais do autor (que se aproxima do right of publicity) perduram pelo prazo de setenta anos, cujo termo inicial é o primeiro dia do ano subsequente ao do falecimento do titular, as sim como o prazo de proteção em relação a obras audiovisuais e fotográficas, prazo es te que deverá ser contado a partir de $1^{\circ}$ de janeiro do ano seguinte ao de sua divulgação (conforme dispõe o artigo 44 da Lei mencionada)

18 Apesar de não incluir expressamente novas tecnologias - por exemplo - transmissões através da internet, por uma questão de razoabilidade também a estes veículos pode se aplicar.
} 
pessoas individualmente, podem ser utilizadas e independem de autorização.

A likeness, por sua vez, representa o que não se enquadra no conceito específico da photograph, servindo como meio protetivo daquilo que se assemelha ao retrato, mas que não é uma representação propriamente dita como a da fotografia, como, por exemplo, a pintura, a escultura, caricatura, a imagem gráfica ${ }^{19}$, etc. Segundo a jurisprudência californiana, os desenhos, se forem suficientemente detalhados, seriam enquadrados na categoria da likeness [conforme o precedente Newcombe v. Adolf Coors Co., 157 F.3d 686, $692-93$ (9 Cir. 1998)], assim como robôs na mesma condição [de acordo com o case Wendt v. Host Intern. Inc., 125 F.3d 806, 810 (9th Cir. 1997)].

No Brasil, a expressão "imagem" tem um sentido mais abrangente. Quando se utiliza o termo "imagem", quer-se expressar a representação visual pessoal, estática ou dinâmica, atual ou passada, hígida ou alterada, total ou parcial (independentemente da técnica de captação utilizada) ${ }^{20}$, sendo também passível de emprego quando se quer afirmar a proteção ao desenho ou figura assemelhada (tal como os robôs referidos em Wendt v. Host Intern. Inc.).

A fotografia, aliás, com um conceito mais restrito, no Brasil é enquadrada na categoria de obra artística, com proteção jurídica tanto como expressão criativa do trabalho do fotógrafo, como quanto produto da exposição de alguém, cuja imagem também é protegida (conforme disposto nos artigos 11; 24, VI e 79 da Lei n. 9.610/1998).

A imagem no direito brasileiro, em sentido amplo, é protegida pela Constituição Federal, em seu artigo $5^{\circ}$, incisos $\mathrm{V}$ e $\mathrm{X}$, os quais reconhecem a inviolabilidade da imagem pessoal e asseguram a possibilidade de postulação de indenização por dano à imagem

A referência constitucional, no Brasil, demonstra o fenômeno da repersonalização do direito civil, como um marco da vabrização dos direitos de personalidade, tanto que, pela primeira vez, o Código Civil passou a regulamentá-lo nos primeiros artigos, como forma de demonstrar que sua leitura é indispensável à correta compreensão das demais normas ali estabelecidas (FACCHINI, 2006).

Assim, conforme dito, no âmbito do Código Civil brasileiro, a proteção está prevista na parte geral, ao tratar das pessoas, especificamente no Capífulo II, dedicado aos direitos de personalidade. A proteção póstuma se dá no âmbito da atribuição de legitimidade processual ao cônjuge ou colateral (até o quarto grau), para exigir a cessação de ameaça ou lesão a direito de personalidade ou indenização por violação ao mencionado direito (conforme dispõe o parágrafo único dos artigos 12 e 20 do Código Civil brasileiro).

\footnotetext{
${ }^{19}$ Disponível em: 〈http://www.thefreedictionary.com/likeness〉. Acesso em: 9 ago. 2015.

${ }^{20}$ Os "elementos visíveis que integram a personalidade humana". (CAHALI, 1999. p. 557)
} 
O resguardo ao nome, concebido como um direito de personalidade de designação pessoal se dá nos artigos 17 e 18, que protege juridicamente o nome, e no artigo 19, que estende, ao pseudônimo, a proteção outorgada ao nome, quando a ele for agregada a notoriedade.

Assim, o nome, como representação designativa de identidade pessoal e que é protegido como um direito de personalidade, não se limita ao constante em registro civil, ou o pseudônimo nas condições antes referidas, podendo também ser utilizado no registro do nome como marca, ou como nome de domínio na internet (que é uma das formas de proteção utilizadas no direito californiano).

O resguardo ao direito de imagem é objeto do artigo 20 do Código Civil brasileiro.

No Brasil, como visto, adota-se um modelo jurídico protetivo de imagem sob uma perspectiva abrangente (sendo a fotografia uma das expressões de imagem, mas não diferenciada na forma mencionada no direito californiano), a qual é protegida em ambos sistemas jurídicos, com a particularidade de que o sistema jurídico californiano "estatutário" é mais restritivo em relação a atribuição do dever de indenizar, pois tem exigido que o uso desautorizado seja consciente, com fins comerciais e que exista uma vinculação direta entre o uso desautorizado e a finalidade comercial existindo restrições quando se trata de um uso póstumo de imagem, ao passo que o Código Civil brasileiro ${ }^{21}$ estabelece dever de indenizar independentemente do propósito de obtenção de lucro (numa manifestação mais protetiva aos direitos de personalidade que o texto do Código Civil californiano) e a proteção ocorre em vida ou após a morte.

Assim, no Brasil, a análise da possibilidade ou não de uso da imagem alheia passa pelo exame de seu contexto (importância fundamental ou secundária do uso), a finalidade do uso da imagem (econômica ou altruísta - mas essa relevância se dá notadamente para arbitramento de eventual indenização), as circunstâncias em que a imagem foi obtida e em que foi veiculada (acidentais ou propositais), o objetivo da divulgação (de atingir negativamente a honra ou de exaltar a honra da pessoa cuja imagem está sendo utilizada), bem como a veracidade e a integridade da imagem e dos demais elementos de informação ${ }^{22}$.

\footnotetext{
${ }^{21}$ Em relação ao limite entre o uso regular ou irregular, dependente ou independente de autorização quanto ao direito de imagem, que excede ao que está sendo proposto, vide, por todos:MIRAGEM, 2005, p. 138.

${ }^{22} \mathrm{O}$ exposto representa uma visão que é es sencialmente personalis ta no que se relaciona aos direitos de imagem, nome e voz. Não se desconhecem, porém, as análises alternativas que são feitas sobre o assunto, e que tratam de uma possível restrição ao viés cultural popular coletivo por parte de quem explora direitos de publicidade, especialmente quando envolvem pessoas públicas e ricas. (MADOW, 1993. p. 205-215).
} 
A voz, por sua vez, tanto no Brasil ${ }^{23}$ quanto no direito californiano, representa a identificação pessoal ${ }^{24}$, por ser a "assinatura" da fonação de uma pessoa, caracterizada pelo som com características particulares que a pessoa produz (cada voz tem a sua ressonância, projeção, qualidade, velocidade e ritmo), sendo certo que essa singularidade permite e cria uma associação imediata entre voz e pessoa ${ }^{25}$.

A proteção jurídica abrange a voz profissional ou amadora, cantada ou falada, mas, na jurisprudência californiana, o termo "voz" se aplica somente à voz real de uma pessoa, não protegendo os imitadores [conforme o precedente Midler v. Ford, 849 F.2d 460, 463 (9 Cir. 1988)]. No entanto, o right of publicity se aplicar à proteção da voz da pessoa imitada, se a voz do imitador evocar a voz do imitado.

Por isso, sob o aspecto do common law californiano, bem como no direito brasileiro, entende-se que uma criação de imagem digital e uma imitação de voz combinada com essa imagem, de forma não autorizada, pode representar violação de direito de imagem, assim como a indústria do entretenimento não pode gerar concorrência desleal em relação a outras sociedades do segmento, ao utilizar um meio digital desautorizado para criar imagem alheia cujo uso não foi autorizado pelo titular (o titular não pode ser "forçado" a autorizar o uso de sua imagem). (MARTIN JR, 1996, p. 122 e 124).

$\mathrm{O}$ direito de imagem expressa-se em duas vertentes, a primeira representando a autodeterminação pessoal quanto a exploração (reprodução, difusão ou publicação), que justifica as legitimas decisões pessoais, e a segunda manifestando-se como direito de defesa,

${ }^{23}$ O artigo 90, $\S 2^{\circ}$, da Lei n. 9.610/1998 protege explicitamente a imagem e voz do artista intérprete ou executante (" $\$ 2^{\circ}$ A proteção aos artistas intérpretes ou executantes estende-se à reprodução da voze imagem, quando associadas às suas atuações"), e o artigo $5^{\circ}$, XXVIII da Constituição Federal estabelece a necessidade de proteção ("nos termos da lei"), da imagem e vozhumanas, "inclusive nas atividades desportivas".

24 "En tal sentido, es legítimo sostener que para el derecho, la imagen es la expresión formal y sensible de la persona y que entra en ese concepto, mucho menos ceñido que el puramente textual o gramatical, la imagen sonora, la imagen que nos dan los gestos, y también la que nos dan partes separadas del cuerpo, como los ojos, los miembros, en tanto ellos importan indicaciones precisas de ciertos personajes, particularmente los famosos. Luego, la voz, las representaciones teatrales, las mímicas, las partes del cuerpo que sean individualizadoras en el caso dado, como otras tantas exteriorizaciones de la imagen personal, entran en el área de la tutela legal". (CIFUENTES, 2008. p. 557-558). Quanto a proteção à voz, vide também a doutrina de Brüggemeier (2009, p. 245). No direito brasileiro, Szaniawski (2005, p. 222) afirma que é possívelencontrar, na jurisprudência brasileira, decisões de "outorga de tutela à própria voz de alguém, além do direito à própria imagem, estando as segurados, entre nós, a proteção de ambas aas manifestações da personalidade humana pela jurisprudência e pela doutrina".

${ }^{25}$ Em Midlerv. Ford afirmou-se que a voz seria tão distinta e pessoal como um rosto, apresentando-se como um dos modos mais palpáveis em que a identidade se manifesta: "um amigo é imediatamente conhecido por algumas palavras ao telefone" [Midler v. Ford, 849 F.2d 460, 463 (9th Cir. 1988)], disponívelem: http://cyber.law.harvard.edu/people/tfisher/1988\%20Midler.pdf, acesso em 9 de agosto de 2015. Esse caso trata da contratação de uma cantora que fez a imitação da voz da cantora Bette Midler, na música "Do You Want To Dance", em um comercial da Ford Motor Company, veiculado nos Estados Unidos da América em 1985]. Veja-se que não foi usado o nome ou a imagem de Midler, mas a similitude da voz, fazendo com que as pessoas se confundis sem, achando que a música estava sendo cantada por Midler, foi entendido como uma conduta geradora de dano à cantora cuja voz foi imitada. 
para que outros não utilizem desautorizadamente tais atributos (SILVA, 2012, p. 283), o que será visto no próximo tópico.

\section{EXISTE UM DIREITO À IMAGEM PÓSTUMO?}

A pesquisa exposta demonstra que o direito californiano é restritivo em matéria de proteção póstuma aos direitos de imagem.

A doutrina costuma dizer, porém, que um right of publicity post-mortem depende do domicîilio do titular da imagem no momento de sua morte, e a especificação do sistema jurídico de qual estado dos EUA se aplica a um determinado caso é necessária, a fim de descobrir quem tem o direito de propriedade em relação à imagem da pessoa falecida. Nova Iorque, por exemplo, não reconhece right of publicity póstumo, e as recentes decisões do United States District Court for the Central District of California, na concessão de umimaginável right of publicity, indicam que a Califórnia pode ser o melhor lugar para celebridades viverem e morrerem, por força dessa proteção maior que em outros estados dos EUA (HENDERSON, 2009, p. 167).

Em Milton H. Greene Archives, Inc. v. CMG Worldwide, Inc., manteve-se o right of publicity post-mortem na Califórnia para uma celebridade falecida. Porém, como ela faleceu em Nova Iorque, foi considerado que seu direto de publicidade extinguiu-se com a morte, o que evidencia a necessidade de Nova Iorque adotar um right of publicity post-mortem protetivo ao titular da imagem, para evitar o risco de domicilio de uma celebridade seja determinante à existência ou não desse direito ${ }^{26}$.

De acordo com Henderson, uma tendência crescente e recente é a de aplicar anabgicamente as consequências jurídicas do direitos de propriedade aos right of publicity. Cortes judiciais e juristas têm justificado esta comparação com base no propósito comum de ambos regimes jurídicos, que é o de proteger um indivíduo contra a apropriação indevida de valor comercial de seu nome ou imagem, concedendo-the o controle exclusivo sobre o seu nome ou imagem. Por conseguinte, os danos no right of publicity são mensurados conforme o prejuízo para o valor de negócio da identidade pessoal Como a maioria das formas de propriedade são transferíveis com a morte, esta linha de raciocínio permitiria a conclusão de que o direito de propriedade de um indivíduo, seu nome ou imagem também o seriam (HENDERSON, 2009, p. 175).

\footnotetext{
${ }^{26}$ Segundo Henderson (2009, p. 177 e 193), há dois projetos em tramitação perante o legis lativo de Nova Iorque, para a criação de um direito de publicidade póstumo.
} 
No Brasil, o texto do Código Civil confirma que a "existência da pessoa natural termina com a morte" (artigo $6^{\circ}$ ). Mas, ainda que a pessoa falecida possa ser sujeito de relações jurídicas - pois fim da vida lhe retira a personalidade jurídica em sentido subjetivo -, resistem à morte os seus legítimos interesses jurídicos provenientes dos direitos de personalidade, os quais transcendem ao falecimento, subsistem, produzem efeitos jurídicos e podem influenciar e causar ingerências voluntárias ou involuntárias no curso social (SOUZA, 1995, p. 189, 193 e 194$)^{27}$.

A sequência da produção de alguns efeitos jurídicos póstumos demonstra que não ocorre a extinção da personalidade em sentido objetivo (constituída pelos atributos pessoais essenciais), mas, sim, há a sua projeção "para além da vida do seu titular" (SCHREIBER, 2013, p. 25). O exercício de alguns direitos póstumos se dá com outra titularidade e com características específicas (por isso, constitui-se como uma titularidade extraordinária), porquanto as legíimas pretensões relacionadas aos direitos de personalidade da pessoa falecida (notadamente de defesa, de inibição, de mitigação do dano ou de indenização por danos) podem ser exercidas pelo "cônjuge supérstite, ou qualquer parente em linha reta, ou colateral até o quarto grau" (artigo 12, caput e parágrafo único do Código Civil).

Não se desconhece, no entanto, a crítica que se faz à referida regra, que não refere o companheiro, e que limita os egitimados extraordinários ao rol de herdeiros, evidenciando a nota de patrimonialidade reinante na redação do Código Civil.

Quanto ao fundamento dessa titularidade extraordinária, aguns autores sustentam que ela seria fundada em teorias sobre deveres jurídicos gerais, outros que afirmam a ideia de uma personalidade jurídica parcial pós-morte. Há, ainda, teorias que vinculam esse interesse aos próprios afetados diretamente por condutas atentatórias à memória do falecido ou que consideram os herdeiros ou legatários fiduciários dos direitos de personalidade do falecido ${ }^{28}$.

Porém, entende-se que a tese mais adequada é a que encontra o fundamento na titularidade dos herdeiros ou sucessores em relação a exploração de determinados atributos da pessoa falecida reside na sucessão por "aquisição derivada translativa mortis causa de direitos pessoais" (SOUZA, 1995, p. 367) ${ }^{29}$.

\footnotetext{
${ }^{27}$ Convém destacarque referido autor não refere a interesses juridicamente relevantes relacionados a pessoa falecida, ele menciona que a pessoa falecida teria personalidade física e moral como "bem jurídico", como "objeto dos direitos de personalidade". O cuidado que se deve ter com esse pensamento é o de reduzir os direitos de personalidade e suas expressões a um mero patrimonialismo que se vincula à expressão "bem jurídico".

${ }^{28}$ Vide, por todos (SOUZA, 1995. p. 364) e, quanto às divergências em relação a titularidade do direito violado, veja-se (BELTRÃO, 2014. p. 132-136).

${ }^{29}$ Esse também parece ser o caminho trilhado pela jurisprudência brasileira, revelando-se interessante a perspectiva do Resp. n. 268.660, que trata da atuação da mãe na defesa da imagem e memória da filha (agindo
} 
Ultrapassado esse aspecto (que não influencia o resultado do estudo proposto neste artigo), especificamente quanto ao uso de imagem nome e voz, a regra é a de que o uso depende de autorização, com algumas exceções (por exemplo, se for necessária à administração da justiça ou à manutenção da ordem pública, nos termos do artigo 20 do Código Civil, por escopo científico, didático ou cultural), proteção essa que se estende à imagem de pessoa falecida ${ }^{30}$.

Veja-se que os dispositivos do Código Civil brasileiro albergam uma proteção à imagem, nome e voz em relação a terceiros, mas nada dispõe sobre o uso por aqueles que ficam responsáveis pela administração desses direitos, no lugar do falecido. Pressupõe-se que, por uma questão de razoabilidade e boa-fé, aqueles que sucedem ao falecido, perenizando-o de certa forma, biológica ou juridicamente, tratarão de tais atributos com as cautelas admissíveis.

Mas é necessário também pensar o que pode ser feito quando isso não acontece.

E é justamente em razão do silêncio da lei pelo fato de que o falecido não tem mais voz ativa em relação aos fatos post-mortem, aliado a constatação de que há incompatibilidade entre eventual uso desarrazoado e a legitimidade para vedar abusos (ter-se-ia uma situação em que o "abusador", por autorizar a exploração do uso da imagem e voz, seria a mesma pessoa a quem a lei atribui legitimidade para frear situações de uso irregular de tais atributos, caracterizando conflito de interesses), que convém que, por precaução, providências sejam tomadas, ainda em vida.

Há limites naturais, por parte do titular, para essa atuação preventiva restritiva das pretensões autorizadoras de futuros sucessores, em razão da perda de força efetiva de ação pós-morte, por determinação legal ou, ainda por manifestação de vontade do falecido , mas a manifestação prévia e escrita de vontade para reduzir o espectro de atuação daqueles que

em defesa "alheia"), ao mesmo tempo em que admite uma pretensão que seria da mãe, pelo dano moral próprio decorrente do uso indevido da imagem (agindo em razão de um interes se próprio): CIVIL E PROCESSUAL CIVIL. REEXAME DE PROVA. DIVERGÊNCIA. DANOS MORAIS E MATERIAIS. DIREITO À IMAGEM. SUCESSÃO. SUCUMBÊNCIA RECÍPROCA. HONORÁRIOS. 1. Os direitos da personalidade, de que o direito à imagem é um deles, guardam como principal característica a sua intransmissibilidade. Nem por isso, contudo, deixa de merecer proteção a imagem de quem falece, como se fosse coisa de ninguém, porque ela permanece perenemente lembrada nas memórias, como bem imortal que se prolonga para muito além da vida, estando até acima desta, como sentenciou Ariosto. Daí porque não se pode subtrair da mãe o direito de defender a imagem de sua falecida filha, pois são os pais aqueles que, em linha de normalidade, mais se desvanecem com a exaltação feita à memória e à imagem de falecida filha, como são os que mais se abatem e se deprimem por qualquer agressão que possa lhes trazer mácula. Ademais, a imagem de pessoa famosa projeta efeitos econômicos para além de sua morte, pelo que os seus sucessores passama ter, por direito próprio, legitimidade para postularem indenização em juízo. [...]. STJ. 4a Turma. Recurso Especial n. 268660 / RJ. Relator Ministro César Asfor Rocha. J. em 21/11/2000. DJ 19/02/2001, p. 179. RSTJ, vol. 142, p. 378. RT, v. 789, p. 201. Em sentido contrário ao ora exposto preleciona (SZANIAWSKI, 2005. p. 221).

30 "Le droit à l'image persiste après le décès de la personne représentée, [...]". (MASSON, 2009. p. 243). 
tornaram-se "guardiões" de tais direitos, é instrumento adequado a frear pretensões egoístas e distanciadas das legítimas intenções de seu titular, que pode consignar em que termos o uso de seus atributos de personalidade pode se dar.

A necessidade se acentua quando a imagem, a voz e o nome estão cercados de interesse pela notoriedade, pois tais direitos se revestem de importância a quem deseja preservar qualidades humanas positivas inerentes (inatas ou formadas com o tempo) que constituem sua honra e que, muitas vezes, foram compostas no decorrer da vida e que correm o risco de serem trocadas por dinheiro, sem maiores cautelas.

Eventual ambição do sucessores, aliado a uma natural ânsia curiosa da sociedade, pode se tornar uma armadilha cujo resultado tende a ser nefasto à pessoa falecida, trazendo a necessidade de que o titular do direito de imagem evite que esse atributo seja maculados por interesses meramente egoístas, ilegítimos ou distanciados da vontade da pessoa falecida, e o testamento é o instrumento para esse fim, o que será visto no próximo tópico.

\section{ESTRUTURAÇÃO DO TESTAMENTO NO DIREITO CALIFORNIANO E NO DIREITO BRASILEIRO - FORMA, CONTEÚdO E EXTENSÃO DA PROTEÇÃO À IMAGEM}

Nos Estados Unidos, há uma clássica divisão dos testamentos em Wills e Trusts, esses por sua vez dividem-se em Last Will, Living Will e Living Trust.

O Last Will ou Testament é aquele que em tradução literal significa "última vontade", serve para a distribuição do patrimônio, especificação dos últimos desejos, inclusive a estipulação de tutores aos filhos menores. Muito semelhante ao testamento no Brasil, serve para estabelecer o plano sucessório que desejar, neste uma pessoa fica responsável pela administração da propriedade e é supervisionado pela Corte de sucessões para garantir a vontade do testador.

O Living will é o que se chama no Brasil de Testamento Vital ou Diretivas de última vontade, ou seja, é um documento em que as pessoas firmam para definir tudo relacionado aos cuidados médicos no fim de sua vida, no caso de se tornarem incapazes para tomar suas próprias decisões. (RADOLPH, s/a).

Já o Living trust, pode ser traduzido literalmente como "confiança viva". Neste, o principal foco é designar um administrador dos bens deixados em razão do falecimento ou incapacidade, não havendo necessidade de validação pela Corte. (YAMIN-GARONE, 2009). 
Neste tipo de disposição de última vontade uma pessoa, como instituidor (concedente), estabelece uma relação de confiança através da transferência de ativos para outro (o administrador) que irá administrar e gerenciar esses ativos para benefício de um terceiro (o beneficiário). (HAY, 2010, p. 240). ${ }^{31}$

Tanto nos Estados Unidos quanto no Brasil é possível identificar que a vontade é elemento essencial do testamento e sua importância em território nacional é expressada por Orosimbo Nonato (1957, p. 12) ao destacar: "a faculdade de testar traduz, como sucessão legítima, uma necessidade do consórcio civil e uma satisfação de sentimentos íntimos e profundos do homem". Interpreta-se essa frase como uma necessidade de resgatar a autonomia privada, sendo esse o principal objetivo e fundamento da sucessão testamentária contemporânea (BASTOS, 2014, p. 150). Nos Estados Unidos da mesma forma "o testador é livre para determinar o conteúdo de sua vontade" (HAY, 2010, p. 234).

Deve-se advertir que o testamento promove e efetiva todos os desejos do testador. Como existe o direito de viver em liberdade e autonomia esse direito deve ser preservado no ato de testar. Nesse sentido a pessoa "por meio do testamento, realizaria e expandiria, para além de sua morte e para um futuro no qual já não mais estará, uma das mais importantes ilações de sua personalidade, qual seja, o seu querer e a sua vontade" (CAHALI E HIRONAKA, 2012, p. 264) em relação aos bens com caráter patrimonial e extrapatrimonial Destacam Cahali e Hironaka (2012, p. 264) que esses bens extrapatrimoniais são ainda mais valiosos e merecem total atenção e aceitação das disposições testamentárias nesse sentido.

A própria natureza jurídica do testamento corrobora neste sentido, pois essa manifestação é considerada com um "ato jurídico unilateral, de caráter personalíssimo" (CAHALI E HIRONAKA, 2012, p. 265), característica que consolida o entendimento de poder o testador dispor de bens materiais e imateriais, pois o testamento "só pode emanar, única e exclusivamente da vontade do testador, decharada por ele próprio, pessoal, indelegável e diretamente" (VELOSO, 2007, p.131)

No testamento, "trata-se da vontade de um vivo, para depois de sua morte. A vontade foi do vivo; os efeitos ocorrem com o falecimento dele." (VELOSO, 2007, p. 126)

Assim a disposição da vontade em não dispor do seu direito de imagem para além de sua morte, ou com prazo definido é totalmente válida e eficaz, pois para o negócio juríd ico ser válido é preciso, nos termos do artigo 104 do Código Civil, agente capaz, objeto lícito,

\footnotetext{
${ }^{31}$ Importante destacarque o Uniform Trust Code, introduzido em 2000, tem por objetivo harmonizar as leis estaduais divergentes e para fornecer um modelo abrangente para os estados seguirem. (HAY, 2010, p. 241). O texto está disponível em: 〈http://www.uniformlaws.org/shared/docs/trust_code/utc_final_rev2010.pdf〉.
} 
possível, determinado ou determinável, forma prescrita ou não defesa em lei.

Ultrapassado o plano da validade, tem-se a eficácia do ato jurídico, pois é nesse plano que há a produção dos efeitos. No caso do testamento, a eficácia se perfectibiliza com a morte do testador.

Nos Estados Unidos, há requisitos bem semelhantes para a validade do testamento, quais sejam: a vontade deve ter sido executada com a intenção testamentária; o testador deve ter tido capacidade testamentária; a vontade deve ter sido executada livre de fraude, coação, abuso ou erro; e a vontade deve ter sido devidamente executada através das formalidades adequadas. (National Paralegal College, s/a) ${ }^{32}$

A tutela da liberdade e autonomia do testador é fundamental A autonomia precisa ser compreendida como princípio jurídico estrutural no direito privado contemporâneo, pois "a autonomia é condição de possibilidade da ordem jurídica de um Estado Democrático de Direito, que conjuga soberania popular e proteção aos direitos fundamentais" (RÜGER e RODRIGUES, 2007, p. 21).

Nevares (2009), ao tratar da função promocional do testamento, afirma que as disposições testamentárias tanto de cunho patrimonial como existencial merecem acolhida de forma a realizar, âmbito da autonomia privada testamentária, a dignidade da pessoa humana.

Cumpre destacar que autonomia da vontade a autonomia privada são consideradas distintas por parte da doutrina. A autonomia privada é gênero do qual a autonomia da vontade é espécie. Amaral Neto (1999) ao distinguir as duas autonomias refere que a autonomia privada está centrada no poder jurídico de autorregulação das pessoas, em razão do exercício da vontade própria, nas relações das quais façam parte, enquanto que a autonomia da vontade tem um núcleo psicológico e, portanto, subjetivo.

Realizadas essas considerações, importante pontuar que o testamento do ator Robin Willians é o chamado Living Trust, ou seja, foi formatado como um testamento privado sem necessidade de validação pelo judiciário californiano, como já indicado acima. Porém, em razão de um desentendimento dos herdeiros, o testamento foi levado para a corte tornando -o público. ${ }^{33}$ Conforme citado anteriormente, o testamento do ator atualmente é de fácil acesso, inclusive pela internet.

\footnotetext{
${ }^{32}$ Sobre os requisitos para o testamento na Califórnia visitar o endereço eletrônico

<http://www.legalzoom.com/wills-state-requirements/california-will.html>.

${ }^{33}$ Notícia disponívelem: <http://www.law360.com/artic les/659532/4-les sons-from-the-robin-williams-estate-

litigation>. Acesso em 10 jul. 2015.
} 
$\mathrm{Na}$ Califórnia o código que regulamenta essa figura de testamento é o Probate $\operatorname{Code}^{34}$ que na divisão 9 trata da Trust Law. Na parte 02, o artigo 15201 deixa claro que "Uma relação de confiança é criada somente se o instituidor manifesta adequadamente a intenção de criar uma relação de confiança". Reforçando a ideia da importância da vontade. No artigo 15203 alerta que "A confiança pode ser criada para qualquer finalidade que não seja ilegal ou contra a ordem pública."

Ao contrário do Brasil em que é pouco comum o uso da sucessão testamentária por "razões de caráter cultural ou costumeiro, folclórico, algumas vezes, psicológico, outras tantas" (CAHALI; HIRONAKA, 2012, p. 265). Nos Estados Unidos é muito comum o uso do testamento, existem, inclusive, inúmeros endereços na internet com formulários eletrônicos para preenchimento do próprio testamento, demonstrando que nos EUA, o uso dos testamentos é mais disseminado e facilitado.

Retomando a ideia de disponibilização da imagem através do testamento importa destacar o questionamento de Bodin de Moraes (s/a, p. 3): “a privacidade garantida pela Constituição a uma pessoa digna, plenamente capaz, não deveria significar, pelo menos em linha de princípio, mais amplo poder de escolha sobre os seus bens mais importantes?"

Neste sentido, compreende-se ser totalmente possível a disposição do direito de imagem pela via testamentária de acordo com a vontade do testador, ou seja, o testamento pode servir para limitar o uso pós morte da imagem.

Entende-se que essa limitação pode ser através de especificações temporais, espaciais e quanto a integridade. ${ }^{35}$

A primeira, especificação temporal determinada ou perpétua. Quando pode o titular limitar a exploração no tempo, seja no sentido de que a possibilidade de seu uso ocorra a partir de um determinado período (por exemplo, a partir de cinco anos a contar da data da morte) ou por um lapso de tempo específico (v.g., por cinco anos a contar da morte, mas, nesse caso, o titular deve explicitar o que deve ocorrer após esse prazo).

A segunda, especificação espacial quando o titular expressa em quais meios de difusão a sua imagem, voz e nome podem ser veiculadas (televisão, internet, outdoor, rádio, jornais, etc.), ou mesmo especifica o veículo ou segmento autorzado ou não autorizado (v.g., a revista $X$, e não a revista $Y$; o segmento infantil, e não o segmento adulto), sendo admissíve 1

\footnotetext{
${ }^{34}$ Disponível em:

$<$ http://leginfo.legis lature.ca.gov/faces/codes TOCSelected.$x h t m l$ tocCode=PROB\&tocTitle=+Probate+Code ++PROB>. Acesso em: 10 ago. 2015

${ }^{35}$ SOARES, Flaviana Rampazzo; BASTOS, Ísis Boll de Araujo. Avanços tecnológicos e proteção post-mortem dos direitos de personalidade, através do testamento. In: III Congresso Brasileiro de Direito Civil: interpretação e protagonis mo da doutrina. Recife, 2015.
} 
que permita amplamente todo e qualquer meio, existente ou que venha a ser criado, que cite expressa e exaustivamente quais são os canais permitidos, ou que restrinja aos existentes, excluindo os que venham a ser criados.

Permite-se também que seja especificado que somente serão permitidas veiculações por meios e para finalidades altruístas, por exemplo.

Por fim, a especificação quanto a integridade, na qual o titular consignará se permite ou não que sua imagem ou voz sejam manipuladas, recriadas ou tratadas, que sejam utilizadas após manipulação ou tratamento (sobretudo digital), ou mesmo que sejam mescladas com outros elementos de igual ou diferente natureza. Abre-se também a oportunidade para que o titular especifique em que medida essas potencialidades possam ser permitidas ou utilizadas.

Esse é o cenário exemplificativo das potencialidades permitidas ao titular, cabendo destacar que não estão na esfera de disponibilidade aqueles casos em que o uso da imagem, da voz e do nome não estiverem contidos na esfera de autodeterminação pessoal aceitável no sistema jurídico, pois a circunscrição dos direitos de personalidade, nesse aspecto, não é distinta daquela que se poderia traçar em vida ${ }^{36}$.

Por isso, não se permite o ato de disposição pós-morte que, por exemplo, venha a tentar restringir a veiculação de imagens relativas a um acontecimento histórico, ou de interesse público rekvante ${ }^{37}$, havendo também restrição relativa a própria incompatibilidade

\footnotetext{
36 "Quanto aos limites do bem da personalidade física e moral do defunto juridicamente tutelada, com vista à credibilidade e à operacionalidade da respectiva tutela jurídica, importa salientar, desde já, que perduram postmortem os limites à personalidade que identicamente vigoravam em vida." (SOUZA, 1995, p. 196, grifos no original).

${ }^{37}$ Independentemente de qualquer questionamento quanto a justiça ou injustiça da decisão, recentemente o STJ entendeu que pode haver uso de uma imagem de pessoa falecida, independentemente de autorização dos herdeiros, se essa imagem retratar um crime que, não obstante tenha ocorrido há aproximadamente cinquenta anos, teve grande repercussão. Ementa: Recurso especial. Direito civil-constitucional. Liberdade de imprensa vs. Direitos da personalidade. Litígio de solução trans versal. Competência do STJ. Documentário exibido em rede nacional. Linha direta-justiça. Homicídio de repercussão nacional ocorrido no ano de 1958. Caso "Aida Curi". Veiculação, meio século depois do fato, do nome e imagem da vítima. Não consentimento dos familiares. Direito ao esquecimento. Acolhimento. Não aplicação no caso concreto. Reconhecimento da historicidade do fato pelas instâncias ordinárias. Impossibilidade de des vinculação do nome da vítima. Ademais, inexistência, no caso concreto, de dano moral indenizável. Violação ao direito de imagem. Súmula n. 403/STJ. Não incidência. [...] 2. Nos presentes autos, o cerne da controvérsia pas sa pela ausência de contemporaneidade da notícia de fatos passados, a qual, segundo o entendimento dos autores, reabriu antigas feridas já superadas quanto à morte de sua irmã, Aida Curi, no distante ano de 1958. Buscam a proclamação do seu direito ao esquecimento, de não ter revivida, contra a vontade deles, a dor antes experimentada por ocasião da morte de Aida Curi, assim também pela publicidade conferida ao caso décadas passadas. 3. Assim como os condenados que cumpriram pena e os absolvidos que se envolveram em processo-crime (REsp. $\mathrm{n}$. $1.334 / 097 / \mathrm{RJ}$ ), as vítimas de crimes e seus familiares têm direito ao esquecimento - se assim desejarem -, direito esse consistente em não se submeterem a desnecessárias lembranças de fatos passados que lhes causaram, por si, inesquecíveis feridas. Caso contrário, chegar-se-ia à antipática e desumana solução de reconhecer esse direito ao ofensor (que está relacionado com sua ressocialização) e retirá-lo dos ofendidos, permitindo que os canais de informação se enriqueçam mediante a indefinida exploração das des graças privadas pelas quais passaram. [...] 6. É evidente ser possível, caso a caso, a ponderação acerca de como o crime tornou-se histórico, podendo o julgador reconhecer que, desde sempre, o que houve foi uma exacerbada
} 
entre a natureza do tipo de direito de personalidade em questão e os próprios pressupostos dessa espécie, tal como ocorre com o direito à vida.

E também é por esse motivo que devem ser respeitados os negócios jurídicos válidos firmados em vida pelo titular, ou mesmo expressões de criação que tenham caído em domínio público $^{38}$. Assim, se o titular dos direitos de personalidade firmou contrato com revista em que amplamente cedeu direitos de imagem, sem restrição, esse uso de imagem é permitido, inclusive para reedições da própria revista, não podendo haver restrição em testamento.

Da mesma forma, se o contrato firmado permitia amplo uso da imagem utilizada para uma novela, permite-se que seja reprisada, ou que os direitos de transmissão sejam negociados com outros veículos, independentemente de nova autorização.

Nessas hipóteses, eventual restrição testamentária não seria eficaz.

Se não houver interesse em limitar de qualquer forma o uso do nome, voz e imagem, a omissão do titular é tida, considerando o sistema jurídico brasileiro atual como uma ampla permissão da exploração por parte dos herdeiros ou eventuais legatários.

O avanço tecnológico e a destreza dos técnicos nessa área viabilizam a utilização cada vez mais perfeita da imagem e da voz. Os titulares desse direito de personalidade, tem a possibilidade, de especificar em vida sua vontade ao uso limitado, ilimitado ou de não uso. $\mathrm{O}$ meio mais adequado para essa tutela é o testamento, este instrumento viabiliza a descrição detalhada da vontade do titular do direito protegendo e resguardando seus interesses.

\footnotetext{
exploração midiática, e permitir novamente essa exploração significaria conformar-se com um segundo abuso só porque o primeiro já ocorrera. Porém, no caso em exame, não ficou reconhecida essa artificiosidade ou o abuso antecedente na cobertura do crime, inserindo-se, portanto, nas exceções decorrentes da ampla publicidade a que podem se sujeitar alguns delitos. [...] 9. Por outro lado, mostra-se inaplicável, no caso concreto, a Súmula n. 403/STJ. As instâncias ordinárias reconheceram que a imagem da falecida não foi utilizada de forma degradante ou desrespeitosa. Ademais, segundo a moldura fática traçada nas instâncias ordinárias - assim também ao que alegam os próprios recorrentes -, não se vis lumbra o uso comercial indevido da imagem da falecida, com os contornos que tem dado a jurisprudência para franquear a via da indenização. 10. Recurso especial não provido. STJ. 4 ${ }^{\mathrm{a}}$. Turma. Recurso Especial n. 1335153 / RJ. Relator Ministro LUIS FELIPE SALOMÃO. J. em 28/05/2013. DJe 10/09/2013. RSTJ vol. 232. p. 440.

38 "[...] a fixação de um limite temporal aos direitos relativos à personalidade de pessoa falecida será uma questão dependente quer de dados de facto sobre a existência dos bens de personalidade em causa, particularmente em face da existência dos bens de personalidade em causa, particularmente em face da própria densidade da personalidade de defunto, quer das convicções sócio-culturais a esse respeito da nossa comunidade jurídica e, se houver interesses conflituantes, de uma ponderação de interesses". (SOUZA, 1995. p. 197).
} 


\section{CONCLUSÕES}

O estudo empreendido demonstrou que, tanto o direito brasileiro, quanto o direito californiano, possuem regramento jurídico específico dos direitos de personalidade.

No direito estadunidense, os aspectos que enfraquecem uma plena proteção à imagem são o fenômeno da fragmentação legislativa, que the retira a unidade que seria recomendável a um pleno amparo da pessoa falecida cuja imagem quer preservar, bem como da diversidade de fundamentos admissíveis (a proteção segundo as regras de proteção de marca; com base no teor da primeira emenda constitucional; de acordo com os precedentes, ou, ainda, pelo próprio teor do Código Civil californiano).

A análise dos fundamentos possíveis, no direito californiano, à proteção da imagem, demonstrou a possibilidade de uso de semelhantes fundamentos para resguardar a imagem de usos indevidos, inclusive no aspecto de se registrar o nome como marca.

No Brasil, a proteção é mais ampla, tendo-se demonstrado que é positivo que o sistema de proteção jurídica seja unificado, mas, o conteúdo e abrangência da proteção da imagem são determinados, em última análise, pelo poder judiciário, quando instado a tratar de conflitos de interesses (notadamente direito de informação versus direito de imagem).

O direito de imagem no Brasil é tutelado pelo sistema vigente, tanto normativo quanto jurisprudencial, inclusive na fase póstuma. Porém, o que se verifica é que os instrumentos postos à disposição para tanto (especialmente o testamento), pouco são utilizados.

É fato que, na contemporaneidade, a manipulação de imagens é um fenômeno irrefreável. Com o inevitável avanço da tecnologia, é preciso (re)pensar as formas de tutela no uso das imagens; e o direito comparado auxilia neste estudo e aprimoramento legis lativo.

A principal forma de tutelar o direito à imagem após a morte do titular do direito, a fim de preservar sua vontade, é o testamento. Precisa-se pensar no direito sucessório atual através de novos paradigmas, pois é certo de que a nota da patrimonialidade foi ultrapassada pela preocupação da tutela da pessoa humana e decorrente possibilidade de disposições de última vontade de cunho extrapatrimonial.

Demonstra-se, assim, que o sistema jurídico brasileiro está apto a proteger o direito de imagem. A generalidade dos dispositivos legais vigentes permitem construções interpretativas em caráter sistemático aptas a corresponder às demandas decorrentes de possíveis violações por uso de tecnologia para criação de imagens de pessoas falecidas. 


\section{REFERÊNCIAS}

AMARAL NETO, Francisco dos Santos. Autonomia Privada. Revista CEJ, v. 3 n. 9 set./dez. 1999. Disponível em:

$\langle$ http./www.jf.jus.br/ojs2/index.php/revcej/article/viewArticle/235/397>. Acesso em 05 jul 2015.

BASTOS, Ísis Boll de Araujo. Constitucionalização do direito civil: mudança de paradigma que afeta a compressão patrimonialista sobre a sucessão testamentária na contemporaneidade. In: BARBEDO, Chaudia Gay (Org.). Debates Contemporâneos sobre direito das sucessões. Porto Alegre: Editora Uniritter, 2014. p. 145 - 156.

BELTRÃO, Silvio Romero. Direitos da personalidade. 2. ed. São Paulo: Atlas, 2014.

BIEDERMAN, Donald E., et. al. Law and Business of the Entertainment Industries. 5. ed. Westport: Praeger, 2007.

BODIN DE MORAES. Maria Celina. Ampliando os direitos da personalidade. Disponível em: < http $/ /$ www.academia.edu/9689598/Ampliando_os_direitos_da_personalidade>. Acesso em: 10 jul. 2015.

BRAATZ, John R. White v. Samsung Electronics America: The Ninth Circuit Turns a New Letter in California Right of Publicity Law. Pace Law Review. 161. v. 15. September 1994. Article 7, p. 161-222.

BRÜGGEMEIER, Gert, et. al Personality rigths in European tort law. Cambridge: Cambridge University Press, 2010.

CAHALI, Yussef Sahid. Dano moral. 2. ed. São Paub: Revista dos Tribunais, 1999.

CAHALI, Francisco José e HIRONAKA, Giselda Maria Fernandes Novaes. Direito das Sucessões. 4 ed. São Paulo: Revista dos Tribunais, 2012.

CAVAlierI FILHO, Sérgio. Programa de Responsabilidade Civil. 7 ed. São Paulo: Atlas, 2007.

CIFUENTES, Carlos. Derechos personalíssimos. 3. ed. Buenos Aires: Astrea, 2008.

CHAKALIAN, Nairi Intellectual Property Law - Newcombe v. Adolf Coors Co. Golden Gate University Law Review, v. 29, Iss. 1 [1999], Article 17, p. 131-138.

FACCHINI NETO, Eugênio. Reflexões histórico-evolutivas sobre a constitucionalização do direito privado. In: SARLET, Ingo Wolfgag (Org.). Constituição, Direitos Fundamentais e Direito Privado. 2 ed. Porto Alegre: Livraria do Advogado, 2006.

FESTAS, David de Oliveira. Do conteúdo patrimonial do direito à imagem - contributo para um estudo do seu aproveitamento consentido e inter vivos. Coimbra: Coimbra Editora, 2009.

GIL, Antonio Carlos. Como elaborar projetos de pesquisa. 5 ed. São Paub: Atlas, 2010. 
GIL, Antonio Carlos. Métodos e Técnicas de Pesquisa Social. São Paulo: Atlas, 1999.

GLANCY, Dorothy J. The invention of the right to privacy. Arizona Law Review, 1979, v. 21, n. 1, p. 2-39.

HAY, Peter. Law of the United States: introduction au droit américain. 3 ed. Pariz: Dalloz, 2010.

HENDERSON, Laurie. Protecting a celebrity 's legacy: living in California or New York becomes the deciding factor. The Journal of Business, Entrepreneurship \& the Law. v. 3. 2009. p. 165-193.

HENEGHAN, Patrick J., WAMSLEY, Herbert D. The service mark alternative to the right of publicity: estate of Presley v. Russen. Loyola of Los Angeles Entertainment Law Review 113 (1982). p. 113-143.

LEWIS, James; CRICK, Paul Media law and ethics in the 21st century: protecting free expression and curbing abuses. Hampshire: Pagrave Macmillan. 2014.

MADOW, Michael Private Ownership of Public Image: Popular Culture and Publicity Rights 81 Calif. L. Rev. 125, 178-238(1993)

MARTIN JR., Thomas Glenn. Rebirth and Rejuvenation in a Digital Hollywood: The Challenge Computer-Simulated Celebrities Present for California's Antiquated Right of Publicity. UCLA Entertainment Law Review, 1996, 4(1), p. 99-135.

MASSON, Jean-Pol Le droit à l'image. In: RENCHON, Jean-Louis. Les droits de la personnalité. Bruxelles: Bruylant, 2009.

MATHEWS, Stanton T.; LANCASTER Kevin. California causes of action. California: James Publishing Inc., 2013.

MIRAGEM, Bruno, Responsabilidade civil da imprensa por dano à honra. Porto Alegre: Livraria do Advogado Editora, 2005.

\section{NATIONAL PARALEGAL COLLEGE. Statutory Requirements for a Valid Written}

Will. Disponível em:

$<$ http $/ /$ nationalparalegal.edu/willsTrustsEstates_Public/Execut ionValid it yCo mponentsOfWill s/StatutoryRequirementsForWill.asp>. Acesso em: 10 ago. 2015.

NEVARES, Ana Luiza Maia. A função promocional do testamento: tendências do direito sucessório. Rio de Janeiro: Renovar, 2009.

NONATO, Orosimbo. Estudos sobre Sucessão Testamentária. Rio de Janeiro: Revista Forense, 1957.

RANDOLPH, Mary. What is a Living Will? Disponível em:

<http//www.alllaw.com/articles/wills_and_trusts/article7.asp> Acesso em 11 ago 2015. 
RAYSMAN, Richard, et al. Emerging Technologies and the Law: Forms and Analysis, v. 1. New York: Law Journal Press: 2002. p. 9-34.

RÜGER, Adnré; RODRIGUES, Renata de Lima. Autonomia como princípio jurídico estrutural. In: FIUZA, Cesar; SÁ, Maria de Fátima Freire de; NOVAES, Bruno Torquato de Oliveira. (Coords.) Direito Civil: Atualidades II (Da autonomia privada nas situações jurídicas patrimoniais e existenciais). Belo Horizonte: Del Rey, 2007.

SCHREIBER, Anderson. Direitos da personalidade. 2. ed. São Paulo: Atlas, 2013.

SILVA, Andréa Barroso. Direito à imagem: o delírio da redoma protetora. In: MIRANDA, Jorge, et. al (org.). Direitos da personalidade. São Paub: Aths, 2012.

SOARES, Flaviana Rampazzo; BASTOS, Ísis Boll de Araujo. Avanços tecnológicos e proteção post-mortem dos direitos de personalidade, através do testamento. In: III Congresso Brasileiro de Direito Civil: interpretação e protagonismo da doutrina. Recife, 2015.

SOARES, Guido Fernando Silva. Estudos de direito comparado (I) o que é a "common law", em particular, a dos EUA. Revista da Faculdade de Direito da Universidade de São Paulo. V. 92. 1997, p. 163-198.

SOUZA, Rabindranath Valentino Aleixo Capelo de. O direito geral de personalidade. Coimbra: Coimbra Editora, 1995.

SZANIAWSKI, Elimar. Direitos de personalidade e sua tutela. 2. ed. São Paulo: Editora Revista dos Tribunais, 2005.

VASCONCELOS, Pedro Pais de. Direito de personalidade. Coimbra: Almedina, 2006.

VELOSO, Zeno. Testamentos: noções gerais, formas ordinárias, codicilo, formas especiais. In: HIRONAKA, Giselda Maria Fernandes Novaes; PEREIRA, Rodrigo da Cunha. (Coord.) Direito das Sucessões. Inventário e Partilha. Teoria, Jurisprudência e Esquemas práticos. Belo Horizonte: Del Rey, 2007.

YAMIN-GARONE, Mary S. Will vs. Living Trust: What's Best for You? Disponível em: <https://www.legalzo om.co m/articles/will-vs- living-trust-whats-best-for-you>. Acesso em 11 ago 2015 . 